\title{
Prevalence and determinants of anemia among women of reproductive age in developing countries of Asia and Africa: A systematic review protocol
}

\section{Savera Savera}

University of Alberta

Sumera Aziz Ali ( $\nabla$ sumeraaziz7@gmail.com )

Columbia University https://orcid.org/0000-0001-8996-7995

\section{Protocol}

Keywords: Anemia, prevalence, determinants, Africa, Asia

Posted Date: April 24th, 2020

DOI: https://doi.org/10.21203/rs.3.rs-24100/v1

License: (c) (i) This work is licensed under a Creative Commons Attribution 4.0 International License.

Read Full License 


\section{Abstract}

Background The burden of anemia among women of reproductive age (WRA) is significantly higher in developing countries. Studies have been conducted to estimate the prevalence and magnitude of anemia among women of reproductive age and its associated factors mainly in African and Asian countries. However, findings from the existing literature are not synthesized in a systematic way to make evidencebased decisions. Given the high burden of anemia in Asian and African countries and an enormous amount of literature on the prevalence and determinants of anemia, there is a need to undertake a systematic review on prevalence and determinants of anemia among WRA in developing countries of Asia and Africa. Hence, the objective of this study is to conduct a systematic review on the prevalence and determinants of anemia among WRA in developing countries of Asia and Africa. This synthesis of literature will help to understand the determinants of anemia to design targeted and context-based interventions primarily for WRA. In addition, this systematic review will also assist policymakers, stakeholders and managers to make informed and evidence-based decisions mainly in developing countries of Asia and Africa.

Methods The review will focus on assessing the burden of anemia and its determinants in the developing countries of Asia and Africa. PubMed, CINAHL Plus, Science Direct, Medline and Cochrane will be explored using a detailed search strategy. A study will be considered eligible, if it will be a primary epidemiological research conducted through quantitative observational study designs (cross-sectional, case-control or cohort studies) on prevalence and determinants or only determinants of anemia among WRA (15-49 years) in the developing country of Africa or Asia and published in the English language in a peer-reviewed local or international journal from 2000 to 2020.

Discussion This systematic review will provide an opportunity to critically appraise and synthesize the findings from individual studies on the prevalence and determinants of anemia to finally generate a summary. These aggregated findings, in turn, can guide practice and inform policymakers to make evidence-based decisions to address the problem of anemia among women of reproductive age. The results of the review will be disseminated through presentations and peer-reviewed publications.

\section{Background}

Anemia is a major public health concern among women of reproductive age (WRA) and is associated with high maternal and infant morbidity and mortality (Cappellini \& Motta, 2015; Milman, 2011). Anemia occurs when the number and size of red blood cells or the hemoglobin $(\mathrm{Hb})$ concentration fall below an established cut-off value, consequently impairing the capacity of the blood to transport oxygen to the body (Beutler \& Waalen, 2006; Cappellini \& Motta, 2015). The World Health Organization (WHO) has defined anemia as $\mathrm{Hb}$ levels of $<12.0 \mathrm{~g} / \mathrm{dL}$ among WRA (World Health Organization, 2011). According to the WHO estimates, about half a billion WRA are anemic worldwide, of those around 20.2 million women are severely anemic with a higher burden in low-middle-income countries (World Health Organization, 2015). More specifically, anemia affects nearly two-thirds of WRA in developing countries (Baig-Ansari et 
al., 2008). Moreover, estimates in high-risk populations in developing countries suggest that total anemia prevalence may be as high as $50 \%$ to $80 \%$, with as many as $10 \%$ to $20 \%$ having moderate to severe anemia (Kassebaum et al., 2014).

South-East Asia carries a high burden of anemia among WRA (41.9\%), followed by African and Eastern Mediterranean regions (World Health Organization, 2015). The existing research studies conducted in South-Asian countries depict that two-thirds of WRA suffer from iron deficiency anemia, which is the highest prevalence in the world (Bondevik et al., 2000; Dreyfuss et al., 2000). For example, literature shows that around $75 \%$ of women of reproductive age are anemic in rural areas of Pakistan (Baig-Ansari et al., 2008). Furthermore, another study conducted in one of the rural areas of Pakistan reported that $77 \%$ of Pakistani women are anemic; of this $20.8 \%$ of the women were found to have mild anemia and $56.5 \%$ of the women were suffering from moderate to severe anemia (Parks et al., 2018). Furthermore, a recently conducted national nutritional survey in Pakistan revealed that $41.7 \%$ of WRA are anemic, with a slightly higher proportion in rural areas (44.3\%) as compared to urban areas (40.2\%) (United Nations International Children's Emergency Fund, 2019). Similarly, studies from India show that the prevalence of anemia among WRA ranges from $50 \%$ to $90 \%$ across different geographic areas of India (Bentley \& Griffiths, 2003; Panja et al., 2019; Panyang et al., 2018). Likewise, community-based cross-sectional studies conducted in Ethiopia depict that $34.5 \%$ to $56.8 \%$ of the WRA are suffering from anemia across different parts of Ethiopia (Addis Alene \& Mohamed Dohe, 2014; Getachew, Yewhalaw, Tafess, Getachew, \& Zeynudin, 2012; Haidar, 2010). Similarly, one study from Uganda found that $63.1 \%$ of women are anemic, and another study from Bangladesh revealed that more than a third of women are anemic in Bangladesh (Chowdhury et al., 2015).

There is a complex impact of anemia on the health of women and children (Allen, 2000). The consequences of anemia vary according to the type and severity of anemia among both pregnant \& nonpregnant women of reproductive age (Kalaivani, 2009; Kozuki, Lee \& Katz, 2011). Anemia can lead to multiple adverse consequences among WRA by adversely affecting their quality of life as well as their reproductive capacity, resulting in serious maternal and perinatal outcomes (Ndegwa, 2019; Osungbade \& Oladunjoye, 2012). Several studies have shown that anemia among pregnant women can result in poor maternal and fetal outcomes such as intrauterine growth retardation, stillbirths, low-birth-weight, prematurity, intrauterine fetal death, abortion, perinatal mortality, post-partum hemorrhage, and puerperal pyrexia (Beckert, Baer, Anderson, Jelliffe-Pawlowski, \& Rogers, 2019; Hare, Freedman, \& Mazer, 2013; Kassa, Muche, Berhe, \& Fekadu, 2017; Kavle et al., 2008; Tunkyi \& Moodley, 2018). For instance, a review of observational studies found a linear association between maternal anemia and maternal mortality, with each $10 \mathrm{~g} / \mathrm{L}$ increase in maternal hemoglobin associated with a $29 \%$ reduction in maternal mortality (Black et al., 2013). Likewise, findings from a systematic review revealed that $25 \%$ of low birth weight, $44 \%$ of preterm deliveries, and $21 \%$ of perinatal mortality are attributable to anemia during pregnancy in low-income countries (Rahman et al., 2016).

The burden of anemia is significantly higher in developing countries due to factors such as insufficient diet and low intake of foods containing iron, folic acid, and vitamin B12 (Baig-Ansari et al., 2008; Ismail, 
Kahkashan, Antony, \& Sobhith, 2016). In addition, normal physiological changes of pregnancy, consumption of smokeless tobacco, hemoglobinopathies, malaria, HIV, and hookworm infestation can also contribute to anemia among WRA (Anchang-Kimbi et al., 2017; Velikkakam et al., 2017; Shedge \& Kulkarni, 2017; Velikkakam, Fiuza, \& Gaze, 2017; Zhang et al., 2003). Additional factors that predispose WRA to anemia include differences in lifestyles, socio-demographic factors, hygiene conditions, and genetic susceptibility (Baig-Ansari et al., 2008; Ismail, Kahkashan, Antony, \& Sobhith, 2016). For example, studies have found that extremes of age and parity predispose a woman to become anemic (Chowdhury et al., 2015; Kamruzzaman, Rabbani, Saw, Sayem, \& Hossain, 2015). Similarly, women with no or primary education are more likely to be anemic as compared to educated women, and also women from low socioeconomic status are more anemic when compared to women from higher socio-economic status in different studies conducted across the world (Irfan, Muhammad, Khan, \& Mudassir, 2013; Lover, Hartman, Chia, \& Heymann, 2014).

Despite various efforts, anemia has improved minimally (by only $0.2-0.3$ percentage points per year) in the past two decades (Mason, Martorell, Saldanha, \& Shrimpton, 2013). In addition, multiple interventions have shown to reduce the prevalence of anemia worldwide by $12 \%$ between 1992 and 2011, these efforts did not have a similar impact in low and middle-income countries (World Health Organization, 2014). Therefore, more innovative and cause-specific interventions are required to address the increasing burden of anemia in these countries, and to achieve the World Health Assembly target of a $50 \%$ reduction of anemia among WRA by 2025 (World Health Organization, 2014).

To design such interventions, it is crucial to understand the determinants or factors of anemia, which have been studied individually by different researchers in their independent studies. Multiple studies have been conducted to estimate the prevalence and magnitude of anemia among women of reproductive age and its associated factors in developing countries (Alflah, Wahdan, Hasab, \& Tayel, 2017; Ayoya, Spiekermann-Brouwer, Traoré, Stoltzfus, \& Garza, 2006; Baig-Ansari et al., 2008; Bharati, Som, Chakrabarty, Bharati, \& Pal, 2008; Kassa, Muche, Berhe, \& Fekadu, 2017; Piammongkol, Chongsuvivatwong, Williams, \& Pornpatkul, 2006). These independent studies provide a plethora of valuable evidence on the burden and determinants of anemia among WRA mainly in African and Asian countries. However, findings from the existing literature are not synthesized in a systematic way to make evidence-based decisions. Therefore, it is crucial to synthesize the literature on the prevalence of anemia and its determinants in a systematic way to make informed decisions. Thus, the first and foremost step would be to synthesize or aggregate findings from a pool of quantitative studies on the prevalence and determinants of anemia across the range of sociodemographic, biological and nutritional domains. This synthesis of literature will help to understand the determinants of anemia to design targeted and contextbased interventions primarily for women of reproductive age residing in developing countries. In addition, this systematic review will also assist policymakers, stakeholders and managers to make informed and evidence-based decisions. This, in turn, will prepare them to design cost-effective and sustainable public health interventions to reduce the high burden of anemia among women of reproductive age mainly in developing countries of Asia and Africa. 


\section{Research Question}

Given the high burden of anemia in Asian and African countries and an enormous amount of literature on the prevalence and determinants of anemia, there is a need to undertake a systematic review on the topic of prevalence and determinants of anemia among women of reproductive age in developing countries of Asia and Africa. Hence, my objective is to conduct a systematic review on the prevalence and determinants of anemia among women of reproductive age in developing countries of Asia and Africa. The specific research question for this review is: What is the prevalence and determinants of anemia among women of reproductive age in developing countries of Asia and Africa?

\section{Material And Method}

The protocol has been designed and reported according to the Preferred Reporting Items for Systematic Reviews and Meta-analyses Protocols (PRISMA-P) checklist (Moher et al., 2015) (Figure 1).

The review will focus on assessing the burden of anemia and its determinants in the developing countries of Asia and Africa. Additionally, this review will provide a high level of evidence on the prevalence and determinants of anemia. This, in turn, will help to make judgments about the evidence and inform recommendations to address the high burden of anemia among women of resource-poor settings.

\section{Eligibility Criteria}

We will undertake a systematic review on the prevalence and determinants of anemia among women of reproductive age (WRA) in Asian and African developing countries. The criteria to define a developing country are based on the World Bank's 2018-guidelines of country classification. Overall, the eligibility criteria are grouped into nine categories including population, intervention, outcome, and settings, etc. (Table 1). More specifically, a study will be considered eligible for inclusion, if it is primary epidemiological research conducted through quantitative observational study designs (cross-sectional, case-control or cohort studies) on prevalence and determinants or only determinants of anemia among WRA (15-49 years) in the developing country of Africa or Asia and published in the English language in a peer-reviewed local or international journal from 2000 to 2020 . An inclusion/exclusion screening form is given in Table 2.

\section{Information sources and search strategy}

An electronic systematic literature search will be carried out to measure the prevalence and determinants of the anemia among WRA in developing countries of Asia and Africa. Although there are a large number of databases to search articles on the given research topic, we will search five large electronic databases including PubMed, CINAHL Plus, Science Direct, Medline and Cochrane for the current systematic review. These databases will be explored using a detailed search strategy including search terms or combinations. In addition, within these databases, we will approach relevant journals such as The Lancet, Blood Journal, British Medical Journal, Gastroenterology Journal, Nature, PLOS-Medicine, Journal of 
Clinical and Diagnostic Research, The New England Journal of Medicine, Nature \& Nature Medicine, Clinical Infectious Diseases and Annals of Internal Medicine. Moreover, the reference list of included records will also be appraised to identify relevant articles.

The databases will be searched by two researchers independently. The search strategy will be piloted to ensure sufficient specificity and sensitivity. More specifically, articles will be searched using the combination of search terms set out for the defined research question. The preliminary search strategy is illustrated in Table 3. These search items are grouped according to PICOS criteria: 1) Population (WRA), 2) Intervention /Exposure (determinants), 3) Comparison group (non-anemic women), 4) Outcome (anemia), and 5) Settings (developing countries of Asia and Africa). We have identified four major concepts (anemia, WRA, determinants, and developing countries) and their synonyms such as low hemoglobin/hematocrit level (anemia), married women/married pregnant women/ married non-pregnant women (WRA), factors/predictors/co-variates/causes (determinants) and low-middle income countries/low-income countries/less developed countries (developing countries). In addition, we will also consider using different spellings of major concepts such as anemia vs anaemia and hemoglobin vs haemoglobin, etc. to capture relevant articles. This will be followed by combining the major concepts using combinations (AND, OR) germane to the research question. Moreover, we will use truncation (*) to identify more research articles with the same root word. Additionally, indexed keywords in the Medical Subject Headings (MeSH) will be used to ensure uniform search terms.

As an example, to capture the relevant article in a given database following simple search term can be used using major concepts and combinations:

Example 1: (anemia*) AND (determinants OR factors OR predictors OR risk factors) AND (women of reproductive age OR married* OR pregnant*) AND (developing countries).

Example 2: (women of reproductive age* OR pregnant* OR married* OR non-pregnant* OR 'married pregnant woman' OR 'married non-pregnant woman') AND (determinants OR factors OR causes OR predictors) AND (anemia* OR iron deficiency anemia*) AND (Developing African countries OR low and middle-income Asian countries) (Table 3).

We will also apply search limits or filters on publication year (2000-2020), language (English), age group (15-49 years), gender (females) and type of studies (quantitative observational) to include eligible articles in the search. Moreover, to make my search efficient, we will use pre-defined filters (developed by few researchers using possible synonyms regarding some major concepts) on the major concepts such as population or region. Examples of such filters relevant to my topics are given in Table 4.

\section{Study selection}

Citation management system (Endnote software) will be used to manage the records exported from all the electronic databases(Yali, 2004). In the first step, all the studies will be screened by study titles using 
the Endnote software. The shortlisted studies will then be screened by study abstracts. Lastly, the full text of selected studies will be retrieved and screened against the eligibility criteria. In order to ensure the reliability of screening articles among the two reviewers, a pre-defined screening form will be developed and pilot testing will be conducted as per the eligibility criteria. Both reviewers will describe outcome measures after reviewing the studies to verify the relevance of the articles. Strong justifications for excluding studies will be provided by each reviewer. Any disagreement between the two reviewers will be resolved by a third reviewer in a consensus meeting. The third reviewer will be consulted to make the final decision about whether the study meets the eligibility criteria for inclusion. The PRISMA flow diagram will be used to report the study selection process.

\section{Data collection process}

A customized data extraction sheet will be filled by two independent reviewers (SA, SAA) for the eligible studies. Data extraction tables of both reviewers will be matched to ensure that all key findings are included in the systematic review. A third evaluator will be involved (JS), if discordant information is observed during the data extraction process. The data extraction sheet will be pilot tested before initiating the data extraction process. Alongside, existing studies on this research area have been reviewed to determine items of the data extraction form. The items included in the preliminary data extraction form include the title of the article, author, publication date, country of study, date of extraction, reviewer name, purpose/aim of the study, study type, study population, prevalence and determinants of anemia and study limitations. The summary of included studies on the prevalence and determinants of anemia among WRA will also be provided in the main results paper.

\section{Quality assessment of eligible studies}

Both reviewers (SA, SAA) will independently assess the quality of each study using the different Newcastle-Ottawa Scales for cross-sectional and cohort studies (Lo, Mertz, \& Loeb, 2014). This scale is used to assess the quality of descriptive and analytical studies by assessing potential sources of bias in the selection, comparability of participants and the assessment of study outcome. Based on this scale, the maximum score for selection is 4 points, while it is 2 points for comparability and maximum score for the outcome is 3 points making a total score of 9 . Each eligible study will be scored against 9 maximum points and study with higher scores will depict high quality.

\section{Synthesis of included studies}

First, the findings of the review will be synthesized narratively. Initially, we will perform a descriptive analysis of all the final included studies to record their main characteristics such as study title, authors, 
publication year, study aim, study methods, sampling strategy, characteristics of study participants, prevalence and determinants of anemia. Then, a narrative synthesis will be carried in which final studies will be grouped under the main heading of four major determinants such as sociodemographic determinants, dietary, reproductive and biological determinants. Firstly, the two independent reviewers (SA, SAA) will read each included study several times to extract data and group-related results. Later, the reviewers will record analytical interpretations of findings to capture emerging themes. Finally, the reviewers will highlight potential determinants of anemia among women of reproductive age in developing countries of Asia and Africa.

\section{Discussion}

A more comprehensive understanding of the prevalence and determinants of anemia is required to improve the health of women especially in developing countries of Asia and Africa. The protocol will lead to a systematic review which synthesizes evidence on the prevalence and determinants of anemia in urban and rural communities of developing countries in Asia and Africa. Systematic review findings will be made publicly available. This systematic review will provide an opportunity to critically appraise and synthesize the findings from individual studies on the prevalence and determinants of anemia to finally generate a summary. These aggregated findings, in turn, can guide practice and inform policymakers to make evidence-based decisions to address the problem of anemia among women of reproductive age. The results of the review will be disseminated through presentations and peer-reviewed publications.

\section{Abbreviations}

WRA: Women of reproductive Age

WHO: World Health Organization

PICOS: Population, Intervention, Comparison, Outcome, and setting

PRISMA-P: Preferred Reporting Items for Systematic Reviews and Meta-analyses Protocols

\section{Declarations}

\section{Ethics approval and consent to participate}

Not Applicable

\section{Consent for publication}


Not applicable

\section{Availability of data and materials}

Materials described in this paper pertain to the study protocol only and there are no raw data reported. The datasets will be collected and analyzed and can be made available from the corresponding author on reasonable request.

\section{Competing interests}

The authors declare that they have no competing interests.

\section{Funding}

No funding

\section{Authors' contributions}

The study was conceptualized by SA \& SAA. SA prepared the first draft of the manuscript and SAA provided her input to improve the manuscript after editing. All authors have contributed to this manuscript, and reviewed and approved the final version of the paper.

\section{Acknowledgements}

None

\section{References}

Addis Alene, K., \& Mohamed Dohe, A. (2014). Prevalence of anemia and associated factors among pregnant women in an urban area of Eastern Ethiopia. Anemia, 2014. 1-7. doi:10.1155/2014/561567

Alflah, Y. M., Wahdan, I. H., Hasab, A. A., \& Tayel, D. I. (2017). Prevalence and Determinants of Anemia in Pregnancy, Sana'a, Yemen. International Journal of Public Health Science (IJPHS), 6(3), 213-220. doi:10.11591/ijphs.v6i3.7931

Allen, L. H. (2000). Anemia and iron deficiency: effects on pregnancy outcome. The American Journal of Clinical Nutrition, 71(5), 1280-1284.

doi: 10.1093/ajcn/71.5.1280s.

Anchang-Kimbi, J. K., Nkweti, V. N., Ntonifor, H. N., Apinjoh, T. O., Chi, H. F., Tata, R. B., \& Achidi, E. A. (2017). Profile of red blood cell morphologies and causes of anaemia among pregnant women at first 
clinic visit in the mount Cameroon area: a prospective cross sectional study. BMC research notes, $10(1)$, 645. doi:10.1186/s13104-017-2961-6

Ayoya, M. A., Spiekermann-Brouwer, G. M., Traoré, A. K., Stoltzfus, R. J., \& Garza, C. (2006). Determinants of anemia among pregnant women in Mali. Food and nutrition bulletin, 27(1), 311.doi:10.1177/15648265060270010

Baig-Ansari, N., Badruddin, S. H., Karmaliani, R., Harris, H., Jehan, I., Pasha, O., . . Goldenberg, R. L. (2008). Anemia prevalence and risk factors in pregnant women in an urban area of Pakistan. Food and nutrition bulletin, 29(2), 132-139. doi: 10.1177/156482650802900207.

Beckert, R. H., Baer, R. J., Anderson, J. G., Jelliffe-Pawlowski, L. L., \& Rogers, E. E. (2019). Maternal anemia and pregnancy outcomes: a population-based study. Journal of Perinatology, 39, 911-919. doi:10.1038/s41372-019-0375-0

Beutler, E., \& Waalen, J. (2006). The definition of anemia: what is the lower limit of normal of the blood hemoglobin concentration? Blood, 107(5), 1747-1750. doi: 10.1182/blood-2005-07-3046.

Bharati, P., Som, S., Chakrabarty, S., Bharati, S., \& Pal, M. (2008). Prevalence of anemia and its determinants among nonpregnant and pregnant women in India. Asia Pacific Journal of Public Health, 20(4), 347-359. doi: 10.1177/1010539508322762.

Black, R. E., Victora, C. G., Walker, S. P., Bhutta, Z. A., Christian, P., De Onis, M., . . Martorell, R. (2013). Maternal and child undernutrition and overweight in low-income and middle-income countries. The lancet, 382(9890), 427-451. doi: https://doi.org/10.1016/S0140-6736(13)60937-X.

Bondevik, G., Eskeland, B., Ulvik, R., Ulstein, M., Lie, R., Schneede, J., \& Kvåle, G. (2000). Anaemia in pregnancy: possible causes and risk factors in Nepali women. European journal of clinical nutrition, 54(1), 3-8. doi:10.1038/sj.ejcn.1600883

Cappellini, M. D., \& Motta, I. (2015). Anemia in clinical practice-definition and classification: does hemoglobin change with aging? Paper presented at the Seminars in hematology.52(4):261-9. doi:10.1053/j.seminhematol.2015.07.006.

Chowdhury, H. A., Ahmed, K. R., Jebunessa, F., Akter, J., Hossain, S., \& Shahjahan, M. (2015). Factors associated with maternal anaemia among pregnant women in Dhaka city. BMC women's health, 15(1), 77. doi:10.1186/s12905-015-0234-x

Cooke, A., Smith, D., \& Booth, A. (2012). Beyond PICO: the SPIDER tool for qualitative evidence synthesis. Qualitative health research, 22(10), 1435-1443.

Dreyfuss, M. L., Stoltzfus, R. J., Shrestha, J. B., Pradhan, E. K., LeClerq, S. C., Khatry, S. K., West Jr, K. P. (2000). Hookworms, malaria and vitamin A deficiency contribute to anemia and iron deficiency among 
pregnant women in the plains of Nepal. The Journal of nutrition, 130(10), 2527-2536. doi:10.1093/jn/130.10.2527

Getachew, M., Yewhalaw, D., Tafess, K., Getachew, Y., \& Zeynudin, A. (2012). Anaemia and associated risk factors among pregnant women in Gilgel Gibe dam area, Southwest Ethiopia. Parasites \& vectors, 5(1), 296. doi:10.1186/1756-3305-5-296

Haidar, J. (2010). Prevalence of anaemia, deficiencies of iron and folic acid and their determinants in Ethiopian women. Journal of health, population, and nutrition, 28(4), 359. doi:10.3329/jhpn.v28i4.6042

Hare, G. M., Freedman, J., \& Mazer, C. D. (2013). risks of anemia and related management strategies: can perioperative blood management improve patient safety? Canadian Journal of Anesthesia/Journal canadien d'anesthésie, 60(2), 168-175. doi:10.1007/s12630-012-9861.

Irfan, U., Muhammad, Z., Khan, M., \& Mudassir, S. (2013). Prevalence of anemia in pregnant women in district Karak, Khyber Pakhtunkhwa, Pakistan. International Journal of Biosciences (IJB), 3(11), 77-83. doi:10.12692/ijb/3.11.77-83

Ismail, I. M., Kahkashan, A., Antony, A., \& Sobhith, V. (2016). Role of socio-demographic and cultural factors on anemia in a tribal population of North Kerala, India. International Journal Of Community Medicine And Public Health, 3(5), 1183-1188. doi:10.18203/2394-6040.ijcmph20161381.

Kalaivani, K. (2009). Prevalence \& consequences of anaemia in pregnancy. Indian Journal of Medical Research, 130(5), 627-633.

Kamruzzaman, M., Rabbani, M. G., Saw, A., Sayem, M. A., \& Hossain, M. G. (2015). Differentials in the prevalence of anemia among non-pregnant, ever-married women in Bangladesh: multilevel logistic regression analysis of data from the 2011 Bangladesh Demographic and Health Survey. BMC women's health, 15(1), 54. doi:10.1186/s12905-015-0211-4

Kassa, G. M., Muche, A. A., Berhe, A. K., \& Fekadu, G. A. (2017). Prevalence and determinants of anemia among pregnant women in Ethiopia; a systematic review and meta-analysis. BMC hematology, $17(1), 17$. doi:10.1186/s12878-017-0090-z

Kassebaum, N. J., Jasrasaria, R., Naghavi, M., Wulf, S. K., Johns, N., Lozano, R., . . Eisele, T. P. (2014). A systematic analysis of global anemia burden from 1990 to 2010. Blood, 123(5), 615-624.

Kavle, J. A., Stoltzfus, R. J., Witter, F., Tielsch, J. M., Khalfan, S. S., \& Caulfield, L. E. (2008). Association between anaemia during pregnancy and blood loss at and after delivery among women with vaginal births in Pemba Island, Zanzibar, Tanzania. Journal of Health, Population, and Nutrition, 26(2), 232.

Kozuki, N., Lee, A. C., \& Katz, J. (2011). Moderate to Severe, but Not Mild, Maternal

Anemia Is Associated with Increased Risk of Small-for-Gestational-Age Outcomes. 
Lover, A. A., Hartman, M., Chia, K. S., \& Heymann, D. L. (2014). Demographic and spatial predictors of anemia in women of reproductive age in Timor-Leste: implications for health program prioritization. PloS one, 9(3), 91252. doi:10.1371/journal.pone.0091252

Mason, J., Martorell, R., Saldanha, L., \& Shrimpton, R. (2013). Reduction of anaemia. The Lancet Global Health, 1(1), 4-6. doi:10.1016/s2214-109x(13)70009-3

Lo, C. K.-L., Mertz, D., \& Loeb, M. (2014). Newcastle-Ottawa Scale: comparing reviewers' to authors' assessments. BMC medical research methodology, 14(1), 45.

Moher, D., Shamseer, L., Clarke, M., Ghersi, D., Liberati, A., Petticrew, M., . . Stewart, L. A. (2015). Preferred reporting items for systematic review and meta-analysis protocols (PRISMA-P) 2015 statement. Systematic reviews, $4(1), 1$.

Milman, N. (2011). Anemia-still a major health problem in many parts of the world! Annals of hematology, 90(4), 369-377.

Ndegwa, S. K. (2019). Anemia \& its associated factors among pregnant women attending antenatal clinic at Mbagathi County Hospital, Nairobi County, Kenya. African Journal of Health Sciences, 32(1), 59-73. Retrived from: https://www.ajol.info/index.php/ajhs/article/view/184953/174290.

Osungbade, K. O., \& Oladunjoye, A. O. (2012). Anaemia in developing countries: burden and prospects of prevention and control. Anemia,115-122. doi:10.5772/29148.

Panja, T. K., Sinha, N. K., Chakrabortty, S., Maiti, S., Dutta, D., Kundu, P., \& Pal, S. (2019). Prevalence of anaemia in varied nutritional state among the women of reproductive ages belonging to low socioeconomic status of rural India. International Journal of Physiology, Nutrition and Physical Education, 4(1): 1639-1643, 29(9.88), 28.70-30.27.

Panyang, R., Teli, A. B., \& Saikia, S. P. (2018). Prevalence of anemia among the women of childbearing age belonging to the tea garden community of Assam, India: A community-based study. Journal of family medicine and primary care, 7(4), 734, 734. doi:10.4103/jfmpc.jfmpc_274_17

Parks, S., Hoffman, M. K., Goudar, S. S., Patel, A., Saleem, S., Ali, S. A., Wallace, D. (2018). Maternal anaemia and maternal, fetal, and neonatal outcomes in a prospective cohort study in India and Pakistan. BJOG: An International Journal of Obstetrics \& Gynaecology.126(6), 737-743. doi: 10.1111/1471. 
Piammongkol, S., Chongsuvivatwong, V., Williams, G., \& Pornpatkul, M. (2006). The prevalence and determinants of iron deficiency anemia in rural Thai-Muslim pregnant women in Pattani Province. Southeast Asian journal of Tropical Medicine and Public Health, 37(3), 553.

Rahman, M. M., Abe, S. K., Rahman, M. S., Kanda, M., Narita, S., Bilano, V., .. Shibuya, K. (2016). Maternal anemia and risk of adverse birth and health outcomes in low-and middle-income countries: systematic review and meta-analysis, 2. The American journal of clinical nutrition, 103(2), 495-504. doi:10.3945/ajcn.115.107896

Shedge, H., \& Kulkarni, S. (2017). Maternal Smokeless Tobacco Use in Pregnancy and Adverse Health Outcomes in Newborn Babies (LBW): A Systematic Review. Asian Man (The)-An International Journal, 11(2), 180-182. doi:10.5958/0975-6884.2017.00029.9

Tunkyi, K., \& Moodley, J. (2018). Anemia and pregnancy outcomes: a longitudinal study. The Journal of Maternal-Fetal \& Neonatal Medicine, 31(19), 2594-2598. doi:10.1080/14767058.2017.1349746.

United Nations International Children's Emergency Fund. (2019, June). National Nutrition

Survey 2018-Key Findings Report. Retrieved from:

https://www.unicef.org/pakistan/reports/national-nutrition-survey-2018-key-findings-.

Velikkakam, T., Fiuza, J. A., \& Gaze, S. T. (2017). Overview of hookworm infection in humans. In Neglected Tropical Diseases, 121-135. doi:10.1007/978-3-319-68493-2_4

World Health Organization. (1992). The prevalence of anaemia in women: a tabulation of available information. Retrieved from:

https://apps.who.int/iris/bitstream/handle/10665/58994/WHO_MCH_MSM_92.2.pdf? sequence=1\&isAllowed $=y$

World Health Organization. (2011). Haemoglobin concentrations for the diagnosis of anaemia and assessment of severity. Retrieved from:

https://apps.who.int/iris/bitstream/handle/10665/85839/WHO_NMH_NHD_MNM_1 1.1_eng.pdf.

World Health Organization. (2014). Global nutrition targets 2025: Policy brief series.Retrieved from:https://apps.who.int/iris/bitstream/handle/10665/149022/WHO_NMH_NHD_14.7_en g.pdf?ua=1.

World Health Organization. (2015). The global prevalence of anaemia in 2011. In The global prevalence of anaemia in 2011. Retrieved from:

https://www.who.int/nutrition/publications/micronutrients/global_prevalence_anaemia_2011/en/ 
Yali, Z. (2004). The Identification and Evaluation of the Kernel Authors of New Technology of Library and Information Service. Data Analysis and Knowledge Discovery, 20(12), 83-84.

Zhang, S. M., Willett, W. C., Selhub, J., Hunter, D. J., Giovannucci, E. L., Holmes, M. D., . . Hankinson, S. E. (2003). Plasma folate, vitamin B6, vitamin B12, homocysteine, and risk of breast cancer. Journal of the National Cancer Institute, 95(5), 373-380. doi:10.1093/jnci/95

\section{Tables}




\begin{tabular}{|c|c|c|}
\hline Attribute & Inclusion Criteria & Exclusion Criteria \\
\hline Population & $\begin{array}{l}\text { All studies including women of reproductive age from } 15 \text { to } 49 \\
\text { years of age. } \\
\text { Studies involving pregnant or non-pregnant women and married } \\
\text { or non-married women of reproductive age from } 15 \text { to } 49 \text { years } \\
\text { of age. }\end{array}$ & $\begin{array}{l}\text { Studies involving children or elderly under the } \\
\text { age of } 15 \text { or over the age of } 49 \text { years. } \\
\text { Studies focused on men of any age. }\end{array}$ \\
\hline Intervention/Exposure & $\begin{array}{l}\text { Studies will be included that have measured the } \\
\text { prevalence/burden of anemia and its determinants or risk } \\
\text { factors or factors or causes or predictors. } \\
\text { Studies will be included that have only measured the } \\
\text { determinants or risk factors or factors or causes or predictors } \\
\text { of anemia. }\end{array}$ & Studies focusing on interventions for anemia. \\
\hline Comparison & The comparison group will be women without anemia. & Not applicable \\
\hline Outcome & $\begin{array}{l}\text { Anemia is measured objectively and defined as } \mathrm{Hb}<12.0 \mathrm{~g} / \mathrm{dl} \\
\text { or Hct }<36 \% \text { among non-pregnant women, and } \mathrm{Hb}<11.0 \mathrm{~g} / \mathrm{dl} \\
\text { or Hct }<33.0 \% \text { among pregnant women. }\end{array}$ & $\begin{array}{l}\text { Studies that have measured outcomes other than } \\
\text { anemia such as nutritional deficiencies, food } \\
\text { insecurity, etc as a proxy indicator of anemia. }\end{array}$ \\
\hline Setting & Studies conducted in developing countries of Asia and Africa. & $\begin{array}{l}\text { Studies conducted elsewhere other than } \\
\text { developing countries of Asia and Africa. }\end{array}$ \\
\hline Study Designs & $\begin{array}{l}\text { Non-experiment observational quantitative studies (cross- } \\
\text { sectional, case-control, cohort), which are powered for the } \\
\text { identified research question of anemia and have primarily } \\
\text { collected data to study the proposed research question of } \\
\text { anemia. }\end{array}$ & $\begin{array}{l}\text { Randomized and non-randomized controlled trials, } \\
\text { pre- and post-test designs, commentaries, } \\
\text { editorials, symposium proceedings, systematic } \\
\text { reviews, secondary articles, and qualitative } \\
\text { studies. }\end{array}$ \\
\hline Language & $\begin{array}{l}\text { Studies available in the English Language as authors are } \\
\text { proficient in this language. }\end{array}$ & $\begin{array}{l}\text { Studies that are not available in English } \\
\text { translation. }\end{array}$ \\
\hline Time period & $\begin{array}{l}\text { Studies published between January } 2000 \text { to December } 2018 \text { to } \\
\text { cover a wide range of recently published literature. }\end{array}$ & $\begin{array}{l}\text { Studies published before January } 2000 \text { and after } \\
\text { December } 2018\end{array}$ \\
\hline Type of journal & $\begin{array}{l}\text { Studies published in the peer-reviewed local and international } \\
\text { journal }\end{array}$ & Studies published in non-peer reviewed journals \\
\hline
\end{tabular}


Table 2: Inclusion and Exclusion screening form

Study Characteristics

Page/

Para/

Figure

\#

Type of study

(Quantitative Observational studies such as cross-sectional studies, case-control studies and cohort studies)
Study Participants

(Studies involving women of reproductive age 15-49 years to study the prevalence and determinants of anemia
Study setting: Developing countries of Asia and Africa

Follow the list of all developing countries of Asia and Africa based on World bank definition of 2018
- cqase control

- cqross-sectional

- cCohort

\section{c Observational study}

cohort
Interventional

study

c Randomized controlled trial

- c Quasiexperimental study

- c Pre-post design c Other design (specify):

- Exploratory

- Descriptive

- Ethnography

- other

Does the study design meet the criteria for inclusion?

Yes c No c àExclude Unclear c

Describe the participants included:

\begin{tabular}{|c|c|}
\hline $\begin{array}{l}\text { Are participants defined as a women of } \\
\text { reproductive age from } 15-49 \text { years? }\end{array}$ & $\begin{array}{l}\text { Yes c No c } \\
\text { Unclear c } \\
\text { Details: }\end{array}$ \\
\hline How is the age or gender defined? & $\begin{array}{l}\text { Details: } \\
\text { Specific age group } \\
\text { and gender (e.g. } \\
\text { men / women): }\end{array}$ \\
\hline $\begin{array}{l}\text { Do the participants meet the criteria for } \\
\text { inclusion? }\end{array}$ & $\begin{array}{l}\text { Yes c No c } \\
\text { àExclude } \\
\text { Unclear c }\end{array}$ \\
\hline $\begin{array}{l}\text { Is the study conducted in developing } \\
\text { countries of Asia and Africa? }\end{array}$ & $\begin{array}{l}\text { Yes c } \quad \text { No c } \\
\text { àExclude } \\
\text { Unclear c }\end{array}$ \\
\hline & $\begin{array}{l}\text { Specify the region: - } \\
\text { Specify the country } \\
\text { :-- }\end{array}$ \\
\hline Prevalence and determinants & \\
\hline $\begin{array}{l}\text { Does the study measure the prevalence and } \\
\text { determinants or predictors or factors or }\end{array}$ & $\begin{array}{l}\text { Yes c } \quad \text { No c } \\
\text { àExclude Unclear c }\end{array}$ \\
\hline
\end{tabular}

Page 16/20 


\begin{tabular}{|c|c|c|}
\hline & \multicolumn{2}{|l|}{ risk factors of anemia? } \\
\hline & $\begin{array}{l}\text { Does the study measure the determinants } \\
\text { or predictors or factors or risk factors of } \\
\text { anemia? }\end{array}$ & $\begin{array}{ll}\text { Yes c } & \text { No c } \\
\text { àExclude } & \text { Unclear c }\end{array}$ \\
\hline \multirow{2}{*}{$\begin{array}{l}\text { Types of outcome measures } \\
\text { (anemia or hemoglobin levels): defined as } \mathrm{Hb}<12.0 \mathrm{~g} / \mathrm{dl} \text { or Hct } \\
<36 \% \text { among non-pregnant women, and } \mathrm{Hb}<11.0 \mathrm{~g} / \mathrm{dl} \text { or Hct } \\
<33.0 \% \text { among pregnant women. }\end{array}$} & List outcomes: & $\begin{array}{l}\text { Give definition of } \\
\text { anemia used by } \\
\text { author: }\end{array}$ \\
\hline & $\begin{array}{l}\text { Do the outcome measures meet the criteria } \\
\text { for inclusion? }\end{array}$ & $\begin{array}{ll}\text { Yes c } \quad \text { No c } \\
\text { àExclude } & \text { Unclear c }\end{array}$ \\
\hline $\begin{array}{l}\text { Year of Publication } \\
2000 \text { to } 2018\end{array}$ & $\begin{array}{l}\text { Is the identified article published from } 2000 \\
\text { to } 2018\end{array}$ & $\begin{array}{l}\text { Yes c No c } \\
\text { àExclude Unclear c } \\
\text { Specify the year----- } \\
---\end{array}$ \\
\hline $\begin{array}{l}\text { Language of the published article } \\
\text { English language }\end{array}$ & $\begin{array}{l}\text { Is the identified article published in English } \\
\text { language? }\end{array}$ & $\begin{array}{l}\text { Yes c No c } \\
\text { àExclude Unclear c } \\
\text { Specify the } \\
\text { language------ }\end{array}$ \\
\hline $\begin{array}{l}\text { Type of journal } \\
\text { Peer reviewed journal (Check from the list of all relevant } \\
\text { journal or google it) }\end{array}$ & Is the identified journal is peer reviewed? & $\begin{array}{l}\text { Yes c No c } \\
\text { àExclude Unclear c } \\
\text { Specify the journal } \\
\text {---- }\end{array}$ \\
\hline
\end{tabular}

Summary of Assessment for Inclusion

\begin{tabular}{|l|ll|}
\hline Include in review c & Exclude from review c \\
\hline Independently assessed by two authors, and then compared? & Differences resolved No c \\
Yes c No c & \\
\hline Notes: & \\
\hline
\end{tabular}




\begin{tabular}{|l|l|}
\hline \multicolumn{2}{|l|}{ Table 3: Search strategy according to PICO criteria } \\
\hline Population & $\begin{array}{l}\text { 'women*' [Mesh] OR 'women*reproductive age*' OR pregnant* OR married* OR non-pregnant* OR 'married woman*' OR } \\
\text { 'married pregnant woman' OR 'married non-pregnant woman' OR 'pregnant women' 'reproductive age' OR 'non-pregnant } \\
\text { women' 'reproductive age' [Mesh]) AND }\end{array}$ \\
\hline $\begin{array}{l}\text { Intervention/ } \\
\text { Exposure }\end{array}$ & $\begin{array}{l}\text { Determinants OR factors OR risk factors [MeSH Terms]) OR causes [MeSH Terms]) OR co-variates [MeSH Terms]) OR } \\
\text { predictors [MeSH Terms]) OR socio-demographic factors [MeSH Terms]) OR demographic determinants [MeSH Terms]) } \\
\text { OR biological factors [MeSH Terms]) OR socio-economic factors [MeSH Terms]) OR dietary factors [MeSH Terms]) OR } \\
\text { nutritional determinants [MeSH Terms]) OR cultural factors [MeSH Terms]) OR multi-causal determinants [MeSH Terms]) } \\
\text { OR prevalence [MeSH Terms]) OR burden [MeSH Terms]) OR incidence [MeSH Terms]) AND }\end{array}$ \\
\hline Outcome & $\begin{array}{l}\text { Anemia OR Hemoglobin levels OR Hemoglobin concentrations OR Hemoglobin status OR low Hemoglobin levels OR low } \\
\text { Hemoglobin concentrations OR 'low hematocrit levels' OR Anemia symptoms OR paleness AND }\end{array}$ \\
\hline Setting & $\begin{array}{l}\text { Developing country OR developing nation OR least developed country OR least developed nation OR less developed nation } \\
\text { OR third world country OR third world nation OR under developed country OR remote region OR low and middle income } \\
\text { country OR under developed nation OR low and middle income nation OR developing countries in Africa OR developing } \\
\text { countries in Asia OR Bangladesh OR Bhutan OR Indonesia OR Timor-Leste OR Kenya OR Ghana OR Kiribati OR Uzbekistan } \\
\text { OR Kosovo OR Vanuatu OR Pakistan OR Vietnam OR India OR Democratic republic of Congo OR Ethiopia OR Zambia OR } \\
\text { Uganda. }\end{array}$ \\
\hline
\end{tabular}


Table 5: Example of pre-defined search filters for some major concepts related to the research question

\section{Search Filter for developing countries in the OVID MEDLINE search:}

egypt/ or morocco/ or tunisia/ or cameroon/ or central african republic/ or chad/ or congo/ or "democratic republic of the congo" / or equatorial guinea/ or gabon/ or "sao tome and principe" / or burundi/ or djibouti/ or eritrea/ or ethiopia/ or kenya/ or rwanda/ or somalia/ or south sudan/ or sudan/ or tanzania/ or uganda/ or angola/ or lesotho/ or malawi/ or mozambique/ or swaziland/ or zambia/ or zimbabwe/ or benin/ or burkina faso/ or cabo verde/ or cote d'ivoire/ or gambia/ or ghana/ or guinea/ or guinea-bissau/ or liberia/ or mali/ or mauritania/ or niger/ or nigeria/ or senegal/ or sierra leone/ or togo/ or honduras/ or nicaragua/ or bolivia/ or kazakhstan/ or kyrgyzstan/ or tajikistan/ or uzbekistan/ or cambodia/ or laos/ or myanmar/ or philippines/ or timor-leste/ or vietnam/ or bangladesh/ or bhutan/ or india/ or afghanistan/ or syria/ or yemen/ or nepal/ or pakistan/ or sri lanka/ or "democratic people's republic of korea"/ or mongolia/ or borneo/ or melanesia/ or papua new guinea/ or vanuatu/ or haiti/ or comoros/ or madagascar/ or sri lanka/ OR (Afghanistan OR Afghani or Afghan OR Angola* OR Bangladesh* OR Benin or Beninese OR Bhutan OR Bolivia* OR Burkina Faso OR Burkinabe or Burundi* OR Cabo Verde OR Cape Verde OR Cambodia* OR Cameroon* OR Central African Republic OR Chad or Chadian or Tchad OR Comoros OR Comoran OR Congo or Congolese OR Cote d'ivoire OR Ivorian OR Djibouti OR Egypt or Egyptian OR El Salvador OR Salvadoran OR Eritrea* OR Ethiopia* OR Gambia OR Gambian OR (Georgia NOT United States) OR Ghana* OR Guinea OR Guinea Bissau* OR Haiti Or Haitian OR Hondura* OR India or (Indian not American) OR Indonesia* OR Kenya* OR Kiribati OR North Korea* OR DPRK OR Kosovo OR Kosovar or Kosovan OR Kyrgyz* OR Laos OR Laotian OR Lesotho OR Mosotho or Basotho OR Liberia* OR Madagascar OR Malagasy OR Malawi* OR Mali OR Malian OR Mauritania* OR Micronesia* OR Moldova* OR Mongolia* OR Morocco OR Moroccan OR Mozambique Or Mozambican OR Myanmar OR Burmese or Myanmarese OR Nepal OR Nepalese OR Nicaragua* OR Niger OR Nigerien OR Nigeria OR Pakistan* OR Papua New Guinea* OR Philippines OR Filipino* OR Rwanda* OR "Sao Tome and Principe" OR San Tomean OR Senegal* OR Sierra Leone* OR Solomon Island* OR Somalia* OR Sri Lanka* OR Sudan or Sudanese OR Swaziland OR Swazi OR Syria or Syrian OR Tajikistan OR Tajik or Tadzhik OR Tanzania* OR Timor Leste OR Timorese OR Togo OR Togolese OR Tunisia* OR Uganda* OR Ukraine or Ukrainian OR Uzbekistan* or Uzbeki OR Vanuatu OR Vietnam* OR West Bank OR Gaza OR Yemen* OR Zambia* OR Zimbabwe*).ti,ab,cp.

\section{Figures}




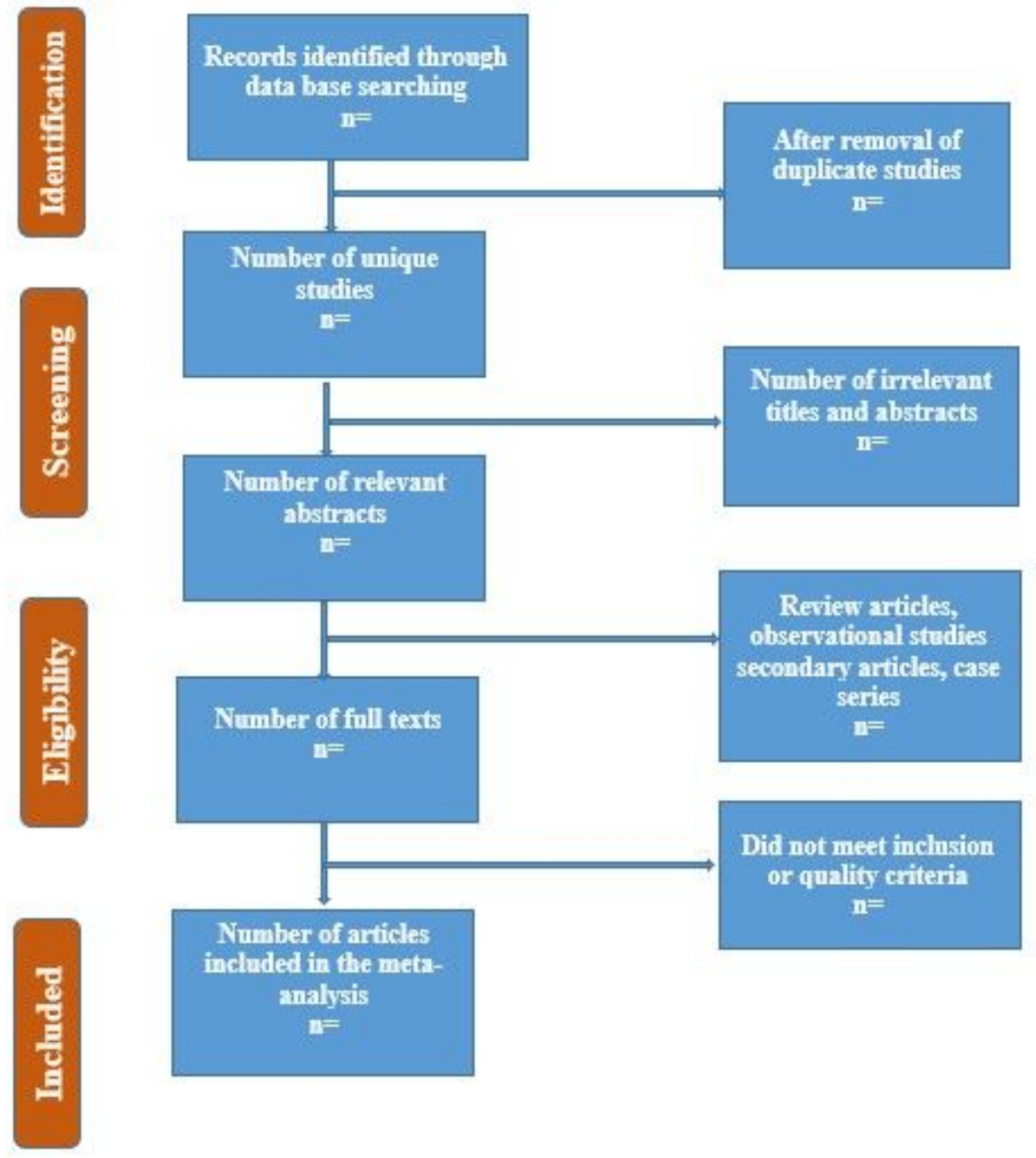

\section{Figure 1}

Flow chart summarizing the identification and selection of papers for systematic review 